\title{
Proceeding
}

9th INSHS International Christmas Sport Scientific Conference, 4-6 December 2014. International Network of Sport and Health

Science. Szombathely, Hungary

\section{Comparison of isometric strength men's upper limbs from the Czech Republic with a group of athletes from different sectors}

\author{
MARTIN VILÍM, MICHAELA JURÁNKOVÁ , PETRA JANÍČKOVÁ \\ Faculty of Sports Studies, Masaryk University, Czech Republic
}

\begin{abstract}
Vilím, M., Juránková, M., \& Janíčková, P. (2015). Comparison of isometric strength men's upper limbs from the Czech Republic with a group of athletes from different sectors. J. Hum. Sport Exerc., 9(Proc1), pp.S308-S313. The aim of this work was to find out the strength difference of the static flexors of the hand between the dominant and non-dominant upper limbs of sportsmen from chosen branches and general population. A group of 20 sportsmen (10 tennis players and 10 javelin throwers) and a group of general population (252 probands from the whole Czech Republic area) took part in the measuring. All tested people were aged $18-29$. The measured values (in $\mathrm{kg}$ ) were obtained by means of a test of handheld dynamometry (digital handheld dynamometer). The measuring showed that sportsmen have higher values of dominant upper limb isometric strength than general population $(58.2 \mathrm{~kg}$ and $53.8 \mathrm{~kg})$. With the nondominant upper limb, the situation is reverse: higher values were discovered with general population (51.2 $\mathrm{kg}$ ) whereas with sportsmen it was only $50.1 \mathrm{~kg}$. A substantially higher difference of isometric strength between the dominant and non-dominant hand was discovered with sportsmen $(8.1 \mathrm{~kg})$; this difference is much smaller $(2.1 \mathrm{~kg})$ with general population. Key words: HANDHELD DYNAMOMETRY, DOMINANT HAND, NON-DOMINANT HAND, MEN.
\end{abstract}

\footnotetext{
Corresponding author. Masaryk University, Kamenice 5, 62500, Brno, Czech Republic E-mail: 259613@mail.muni.cz 9th INSHS International Christmas Sport Scientific Conference, 4-6 December 2014. International Network of Sport and Health Science. Szombathely, Hungary. JOURNAL OF HUMAN SPORT \& EXERCISE ISSN 1988-5202

(c) Faculty of Education. University of Alicante doi:10.14198/jhse.2015.10.Proc1.19
} 


\section{INTRODUCTION}

We generally understand measuring muscle strength as an important indicator for assessing the functional state of muscular tissue and assessment of the seriousness of an individual's clinical status.

The handgrip strength does not function only to assess the function of hands but also to evaluate the rightleft symmetry of strength and general maximum upper limb strength during a common daily activity. To assess it, we use an easy test of the strength of the finger flexors, the value of which we can easily diagnose by means of a handheld dynamometer (Montalcini, Migliaccio, Yvelise, Rotundo, Mazza, Liberato \& Pujia, 2013).

A vast number of scientific studies dealing with handheld dynamometry pursue the topic of skeletal muscles loss and the accompanying muscle strength loss depending on age. A markedly smaller number of the studies deal with the no less important comparison of the right and left hand handgrip depending on the dominance and preference of one side.

The aim of study in Indianapolis was to observe ratio between dominant and non-dominant hand by university baseball players. There were 88 tested subjects, which created experimental and control group. The control group was represented by recreational sport students $(n=44)$ and experimental group was represented by university baseball players $(n=44)$. All the subjects were tested for maximal isometric strength of dominant and non-dominant hand grip. The nondominant-hand grip strength was $89.78 \%$ as strong as the dominant-hand grip strength in the experimental group and was $86.75 \%$ as strong in the control group.

There was no significant difference found after the testing $(p<0,01)$ between dominant and non-dominant hand of university baseball players and control group of students.

The results of baseball players are no different in comparison to control group and are explained particularly by involvement of upper limbs in other sport activities and also by higher use of non-dominant hand by e.g. handling the ball or bat (Jarit, 1991).

Other research is worth mentioning of which the data was gained from the representative adult population sample (1122 men and 1928 women) living in Niterói in Rio de Janeiro. By way of illustration, we present the measured values of the male part of the test sample. The handgrip strength on the hand handheld dynamometer was measured three times for both hands and the highest measured values were used in the analysis. The average values are $42.8 \mathrm{~kg}$ for the right hand and $40.9 \mathrm{~kg}$ for the left hand in the male category. To a certain extent, the handgrip strength increased with age and decreased significantly after the age of 40 and 50 . The highest values of the maximum strength of finger extensors are seen in the fourth decade of life; then a considerable downswing was noted (Schlüssel, dos Anjos, de Vasconcellos, \& Kac, 2008). The measured values are shown in Chart 1.

Table 1. The measured values for the dominant and non-dominant arm (Schlüssel, dos Anjos, de Vasconcellos, \& Kac, 2008)

\begin{tabular}{ccc}
\hline $\mathrm{n}=1122$ & right hand & left hand \\
\hline strength of handrip $(\mathrm{kg})$ & 42,8 & 40,9 \\
\hline
\end{tabular}


It is worth mentioning the study with 769 health adults (women $n=403$, men $n=366$ ), aged 20 to 95 years. Measurement of hand grip was made in neutral position of arm, forearm and wrist by digital hydraulic dynamometer. Results of men group show, that strength of hand grip (right $49 \mathrm{~kg}$, left $47 \mathrm{~kg}$ ) is about $41 \%$ higher than women. In course of life, the hand strength is evolved comparably in both gender, culminates in 35 years and then decreases (Günther, Bürger, Rickert, Crispin, \& Schulz, 2008).

\section{MATERIAL AND METHODS}

The aim of this work is to find out the difference of the static strength of the flexors of the hand between the dominant and non-dominant upper limb of sportsmen from chosen branches. The results will be compared with general population of the Czech Republic.

\section{The characteristics of the groups}

\section{Athletes}

There were 20 sportsmen (10 tennis players and 10 javelin throwers) from the region of Brno who took part in the measuring of isometric strength of upper limbs. The results were obtained between May - August 2014.

\section{General population}

General population is represented by a sample of 252 men from the whole Czech Republic area. The results were obtained between August 2011 - June 2013 within a project investigating the physical activity level of Czech population (CZ.1.07/2.3.00/20.0044).

The age of all the tested people (sportsmen as well as general population) ranged from 18 to 29 years. All subjects were male.

Methods of data collection, data processing and evaluation

We obtained the values of isomeric strength of upper limbs by means of a handheld dynamometry test. The aim of the test was to measure the static strength of flexors of the hand by means of handgrip. A handheld dynamometer (mechanical or digital) is used for testing. The tested person grips the dynamometer so that from one side there can be the pressure of the bent fingers and from the other side the dynamometer can lean on the thenar. Under the direction of an examiner, the tested person clenches his fist isometrically with maximum strength. It is handgrip intensity which is important, not the length. During the grip, a fist should be clenched from circa three-fourths. The person is not allowed to lean the hand with the dynamometer on a different part of the body or on an extrinsic object. The tested person has two attempts for the left as well as the right hand. The more successful attempt is recorded. The measured data are presented in kilograms or newtons.

We carried out the measuring by means of a digital handheld dynamometer MIE Medical Research and the measured values are presented in kilograms.

We processed the obtained results by means of mathematical-statistical and graphical methods. To process the measured values, we used Microsoft Office Excel 2007 and statistical program STATISTICA, version 9.0, by StatSoft (Tulsa, USA). By way of illustration and orderliness, the results were made into charts and graphs. 
The statistical significance was defined $p<0,05$.

\section{RESULTS}

We tested the isometric strength of the flexors of the upper limbs with sportsmen of the chosen sports branches and general population by means of a digital handheld dynamometer. All tested people were aged $18-29$. The measured values are presented in kilograms. The results are shown in Fig. 1, basic statistical characteristics in Tab. 3, box plots in Fig. 2 and 3.

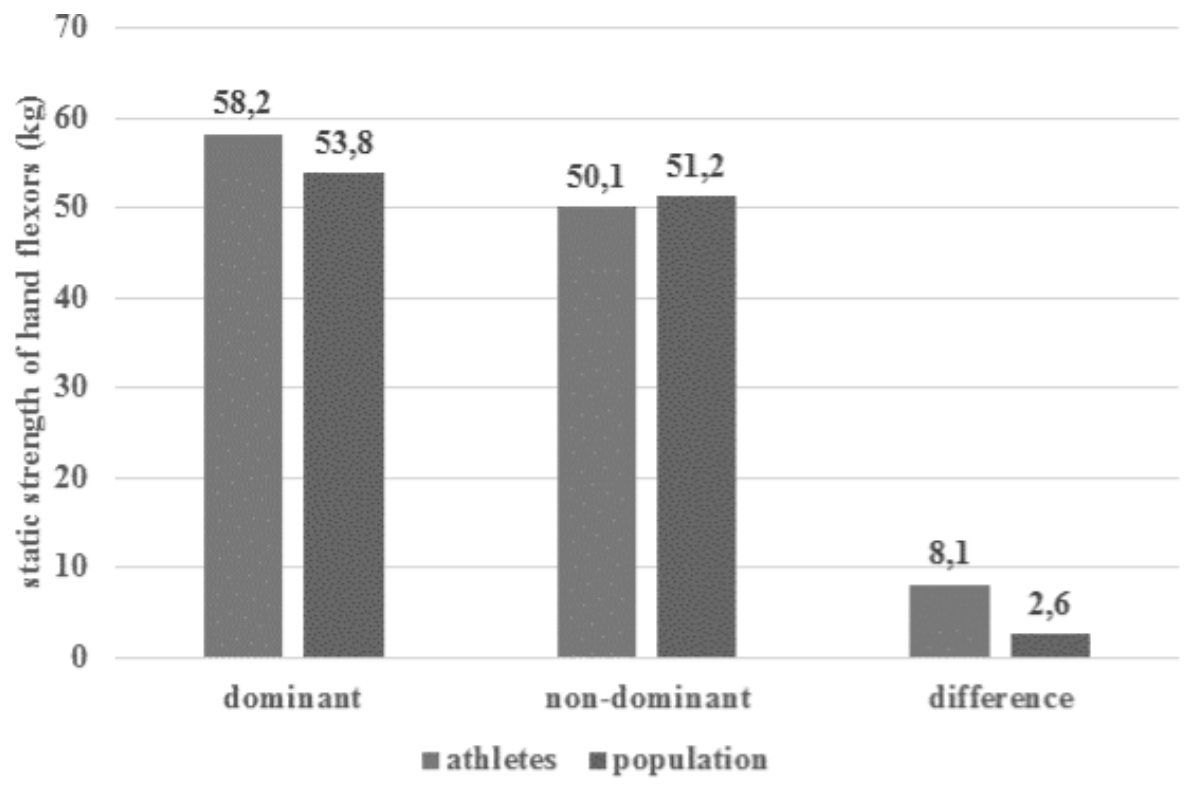

Figure 1. Isometric strength of the upper limbs of sportsmen and general population aged 18 - 29 in the Czech Republic (men)

Table 2. Basic statistical characteristics

\begin{tabular}{cccc}
\hline variable & athletes (average \pm & population (average \pm & $p$ \\
\hline dominant & $58,18 \pm 8,04$ & $53,84 \pm 8,51$ & 0,03 \\
non-dominant & $50,13 \pm 7,44$ & $51,24 \pm 8,70$ & 0,58 \\
index of dominance & $0,54 \pm 0,02$ & $0,51 \pm 0,03$ & 0,001 \\
\hline \multicolumn{4}{c}{ Legend: $p=$ significance level of the rest, $S D=$ standart deviation }
\end{tabular}




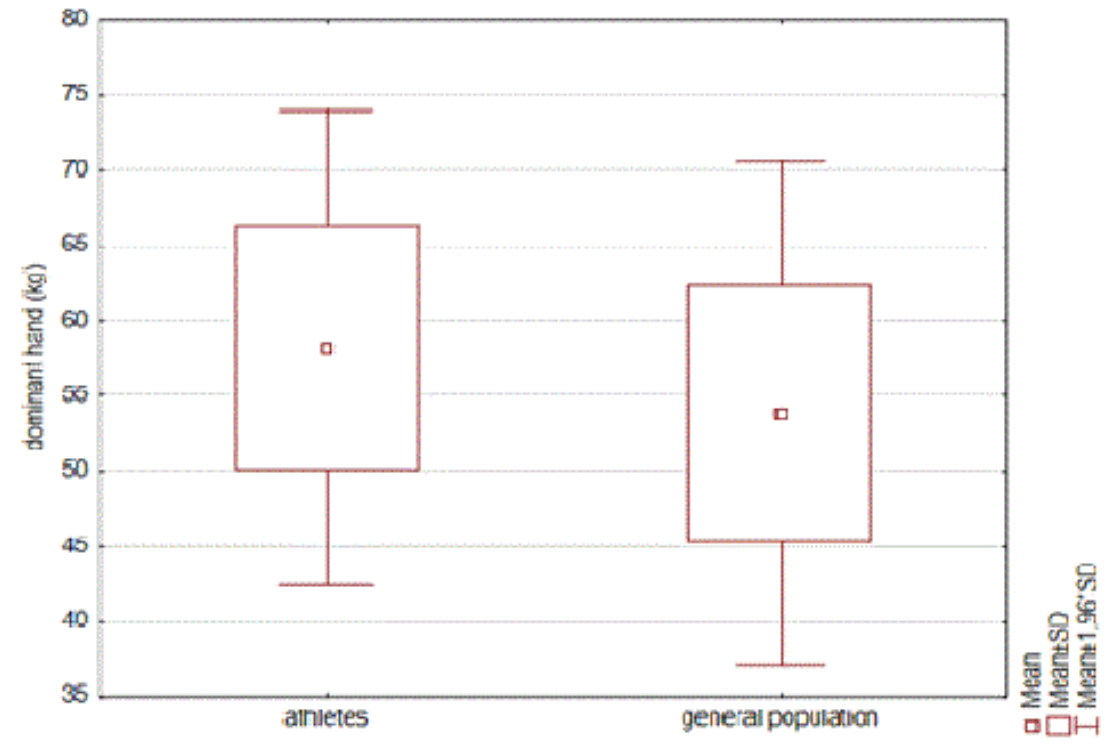

Figure 2. A box plot of the isometric strength of the dominant hand

The results clearly show that in the case of the dominant upper limb sportsmen on average reach higher values of isometric handgrip strength $(58.18 \pm 8.04 \mathrm{~kg})$ than men belonging to general population $(53.84 \pm 8.51 \mathrm{~kg}$, with $p=0.03)$. The differences between the groups reach statistically significant difference.

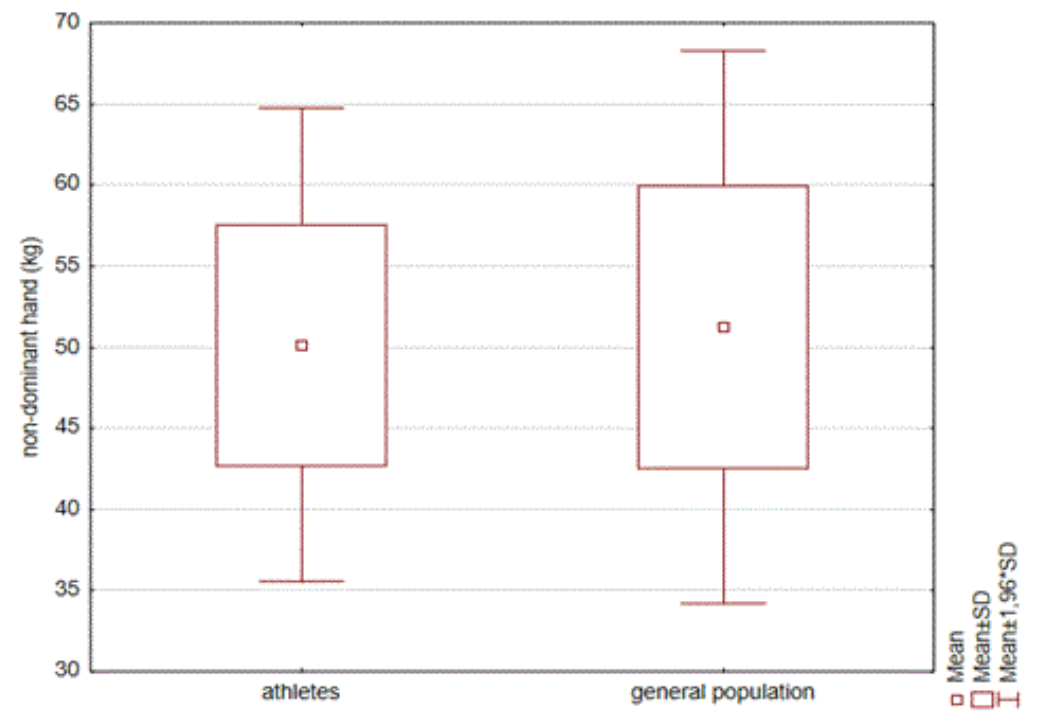

Figure 3. A box plot of the isometric strength of the non-dominant hand

As for the second, non-dominant limb, higher values were measured with general population $(51.24 \pm 8.70$ $\mathrm{kg})$; sportsmen were slightly behind $(50.13 \pm 7.44 \mathrm{~kg}$ with $\mathrm{p}=0.58)$. In this case, the differences do not reach statistical significance.

The difference of the average isometric handgrip strength between the dominant and non-dominant limb of sportsmen $(8.1 \mathrm{~kg})$ is substantially higher than with men who do not do unilaterally straining physical activities $(2.6 \mathrm{~kg})$. 


\section{DISCUSSION}

The measured results indicate that the chosen sportsmen have stronger dominant upper limb whereas higher average values for the non-preferred hand were measured with general population.

We explain this situation particularly by the fact that the sport specialisations (tennis and javelin throwing) of the chosen sportsmen mostly use unilateral strain of the upper part of the body and thus also have higher demands on the upper limb. On the contrary, with general population it is the opposite because in daily life or during recreational physical activities, there are no such specific requirements on the dominant hand and both limbs are strained similarly.

These arguments are also confirmed by the results of the difference of the average handgrip between limbs: while with sportsmen this difference was $8.1 \mathrm{~kg}$ on average, with non-sporting men it was only $2.1 \mathrm{~kg}$ which means negligible.

It is obvious that in sports which are focused on unilateral strain of upper limbs, there will be higher deviations in the handgrip strength of the preferred and non-preferred arm. We believe that significant differences between the dominant and non-dominant upper limb could have negative impact on the sportsmen' state of health. Thus, sportsmen should do compensatory exercises which would be appropriate to be applied during the sports preparation.

\section{CONCLUSIONS}

The aim of this contribution was to compare the difference of the static strength of the flexors of the hand concerning the dominant and non-dominant upper limbs of a group of sportsmen (tennis and javelin throwing) and general population of the Czech Republic aged $18-29$. We focused solely on male population.

The measured values of the dominant hand were higher than those of the sportsmen group (with a $4.4 \mathrm{~kg}$ difference); as for the non-dominant hand, higher values were measured with general population (with a 1.1 $\mathrm{kg}$ difference).

A substantial difference of isometric strength between the dominant and non-dominant hand was discovered with sportsmen $(8.1 \mathrm{~kg})$; the difference with general population is much smaller $(2.1 \mathrm{~kg})$.

\section{REFERENCES}

1. Günther, C. M., Bürger, A., Rickert, M., Crispin, A., \& Schulz, C.U. (2008). Grip strength in healthy caucasian adults: reference values. The Journal of hand surgery, 33(4), pp.558-565.

2. Jarit, P. (1991). Dominant-hand to nondominant-hand grip-strength ratios of college baseball players. Journal of Hand Therapy, 4(3), pp.123-126.

3. Montalcini, T., Migliaccio, V., Yvelise, F., Rotundo, S., Mazza, E., Liberato, A., \& Pujia, A. (2013). Reference values for handgrip strength in young people of both sexes. Endocrine, 43(2), pp.342345.

4. Schlüssel, M.M., dos Anjos, L.A., de Vasconcellos, M.T.L., \& Kac, G. (2008). Reference values of handgrip dynamometry of healthy adults: a population-based study. Clinical Nutrition, 27(4), pp.601-607. 